
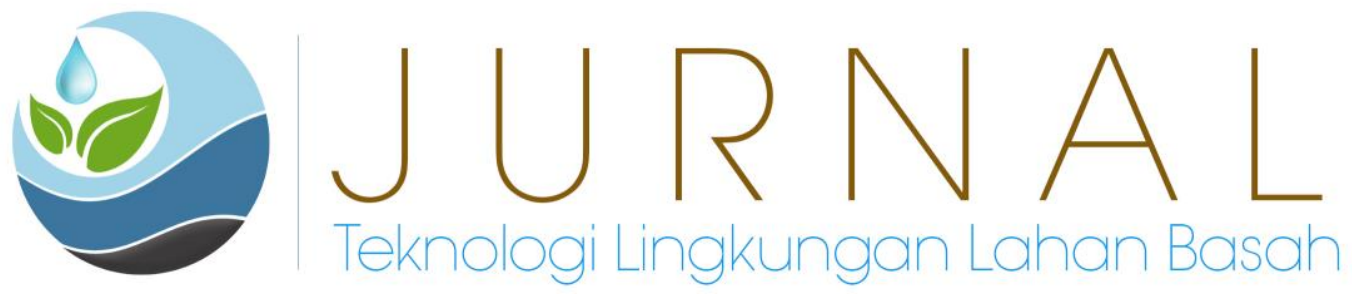

\title{
KAJIAN DAYA TAMPUNG BEBAN PENCEMARAN SUNGAI CIBEUREUM DAS CITARUM DI SEKTOR PERTANIAN
}

\author{
Ajeng Alya Hidrijanti ${ }^{1}$, Iwan Juwana ${ }^{2}$, dan Yenita Sandra Sari ${ }^{3}$ \\ 1, 2.Jurusan Teknik Lingkungan Institut Teknologi Nasional Bandung \\ 3. Prodi Teknik Lingkungan, Universitas Kebangsaan \\ E-mail : ${ }^{1}$ ajengalya9@gmail.com, ${ }^{2}$ yenitasandra@gmail.com
}

\begin{abstract}
Cibeureum watershed is a river located on the border of Cimahi City and Bandung City and empties into the Citarum River. One of the Cibeureum watersheds is from the agriculture sector. Rice fields and gardens in South Cimahi are contributors to pollution in the Cibeureum Sub-watershed. Research on the assessment of pollution load capacity in the Cibeureum Sub-watershed to learn to understand and analyze the burden of the agricultural sector. In addition, the study of the capacity of pollution load in the Cibeureum River has never been carried out, so it is necessary to conduct a study of capacity. Calculation of pollutant load requires data on the area of paddy fields and gardens, emission factors and the number of planting days. Cibeureum watershed is a heavily polluted river after being calculated using pollutant methods with 11.09 results. Pollutant load of Cibeureum Sub-watershed agriculture sector in 2018 is $0.01689 \mathrm{~kg} /$ day BOD, $0.001501 \mathrm{~kg} /$ day Total-N, $0.0008 \mathrm{~kg} /$ day Total-P, and $0.000003 \mathrm{~kg} /$ day TSS. Pollutant load for Cibeureum Sub-watershed agriculture sector in 2018 is $0.103377 \mathrm{~kg} / \mathrm{day}$ BOD, $0.009542 \mathrm{~kg} /$ day Total-N, $0.0048 \mathrm{~kg} /$ day Total-P, and $0.00508 \mathrm{~kg} /$ day TSS. Pollutant load generated from the agricultural sector in the year of allocation will not be excluded from the budget for the development of Cimahi City Regulation Number 4 of 2013 concerning Spatial Planning and Cimahi City Areas for 2012-2032.
\end{abstract}

Keywords: Pollutant Load, Agriculture Sector, Cibeureum Sub-watershed, Indonesia

\begin{abstract}
Abstrak
Sub DAS Cibeureum merupakan sungai yang berada di perbatasan Kota Cimahi dan Kota Bandung dan bermuara ke Sungai Citarum. Pencemar yang masuk ke Sub DAS Cibeureum salah satunya berasal dari sektor pertanian. Sawah dan kebun yang berada di Cimahi Selatan merupakan kontributor terhadap pencemaran di Sub DAS Cibeureum. Penelitian kajian daya tampung beban pencemaran di Sub DAS Cibeureum bertujuan untuk mengetahui dan menganalisis beban pencemar dari sektor pertanian. Selain itu, kajian daya tampung beban pencemaran di Sungai Cibeureum belum pernah dilakukan sehingga perlu dilakukan kajian daya tampung. Perhitungan beban pencemar membutuhkan data luas lahan sawah dan kebun, faktor emisi dan jumlah hari tanam. Status mutu Sungai Cibeureum adalah sungai yang tercemar berat setelah dilakukan perhitungan menggunakan metode indeks pencemar dengan hasil 11,09. Beban pencemar sektor pertanian sawah Sub DAS Cibeureum pada tahun 2018 sebesar 0,01689 kg/hari BOD, 0,001501 kg/hari Total-N, 0,0008 kg/hari Total-P, dan 0,000003 kg/hari TSS. Beban pencemar sektor pertanian kebun Sub DAS Cibeureum pada tahun 2018 sebesar 0,103377 kg/hari BOD, 0,009542 kg/hari Total-N, 0,0048 kg/hari Total-P, dan 0,00508 kg/hari TSS. Beban pencemar yang dihasilkan dari sektor pertanian pada tahun proyeksi tidak dijelaskan akan direncanakan mengalami peningkatan luas lahan dalam Peraturan Daerah Kota Cimahi Nomor 4 Tahun 2013 tentang Rencana Tata Ruang dan Wilayah Kota Cimahi Tahun 2012-2032 sehingga beban pencemar di tahun proyeksi tetap sama seperti tahun 2018.
\end{abstract}

Kata Kunci: Beban Pencemar, Sektor Pertanian, Sub DAS Cibeureum, Indonesia 


\section{PENDAHULUAN}

Daerah aliran sungai adalah suatu wilayah daratan yang merupakan satu kesatuan dengan sungai dan anak-anak sungainya, yang berfungsi menampung, menyimpan, dan mengalirkan air yang berasal dari curah hujan ke danau atau ke laut secara alami, yang batas di darat merupakan pemisah topografis dan batas di laut sampai dengan daerah perairan yang masih terpengaruh aktivitas daratan (UU No.7 Tahun 2004). Daerah Aliran Sungai (DAS) terdiri dari tiga bagian yaitu hulu, tengah dan hilir. DAS Citarum merupakan DAS dengan luas DAS $6.080 \mathrm{~km}^{2}$ (Kurniasih, 2002).

Sungai Cibeureum merupakan sungai yang berada di perbatasan Kota Cimahi dan Bandung yang bermuara ke DAS Citarum. Titik koordinat lokasi Sungai Cibeureum hulu berada pada koordinat $06^{\circ} 54^{\prime} 37.8 \mathrm{~S} 107^{\circ} 34^{\prime} 07.5 \mathrm{E}$, Sungai Cibeureum tengah berada pada koordinat $06^{\circ} 55^{\prime} 09.7 \mathrm{~S} 107^{\circ} 33{ }^{\prime} 55.5 \mathrm{E}$ dan Sungai Cibeureum hilir berada pada koordinat $06^{\circ} 55^{\prime} 55.0 \mathrm{~S}$ $107^{\circ} 33^{\prime} 42.9$ E. Sungai Cibeureum memiliki panjang 24,66 km dari hulu hingga hilir yang melewati Kelurahan Cibeureum, Kelurahan Melong dan Kelurahan Cijerah (DIKPLHD, 2018). Sektor pertanian menjadi salah satu sektor yang menyebabkan pencemaran di Sungai Cibeureum. Adanya kegiatan pertanian di sekitar sub DAS Cibeureum akan mempengaruhi pola pemanfaatan sumber daya air dan akan mengakibatkan dampak negatif yang akan mengganggu keseimbangan tata air.

Sub DAS Cibeureum perlu diidentifikasi melalui kajian daya tampung beban pencemaran air selama 5 tahun sekali untuk mengetahui beban pencemaran air yang dapat diterima oleh Sungai Cibeureum dan memberi solusi untuk membuat rekomendasi terkait strategi pengendalian pencemaran air di Sungai Cibeureum. Selain itu, kajian daya tampung di Sungai Cibeureum belum pernah dilakukan sebelumnya sehingga dibutuhkan kajian daya tampung tersebut.

\section{METODE PENELITIAN}

A. Lokasi Penelitian

Sungai Cibeureum merupakan sungai yang berada di perbatasan Kota Cimahi dan Kota Bandung. Sungai Cibeureum memiliki panjang 24,66 km dari hulu hingga hilir. Sungai Cibeureum melewati Kelurahan Cibeureum, Kelurahan Melong dan Kelurahan Cijerah yang dapat dilihat pada Gambar 1.

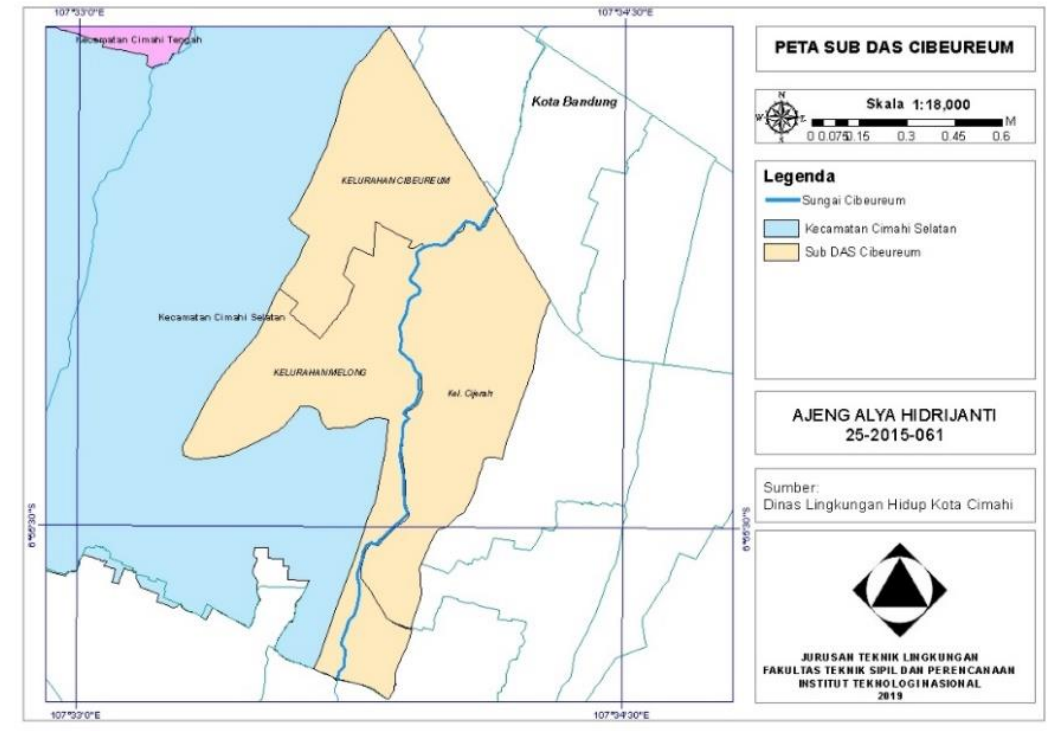

Gambar 1. Peta Lokasi Penelitian 
B. Pengambilan Data

Data yang digunakan dalam melakukan penelitian Kajian Daya Tampung Beban Pencemaran Sungai Cibeureum yaitu menggunakan data primer dan data sekunder. Data primer yang digunakan yaitu data debit sungai di bulan September 2019 serta mengukur dimensi sungai (panjang, lebar, kedalaman). Data sekunder yang dibutuhkan terdiri dari data jumlah penduduk Cimahi dari BPS Kota Cimahi, peta sungai di Cimahi dari DLH Kota Cimahi, data kualitas air Sungai Cibeureum dari DLH Kota Cimahi.

\section{Status Mutu Air}

Status mutu air dapat dihitung dengan menggunakan metode indeks pencemar (Pollution Index) sehingga dapat ditentukan tingkat pencemaran relatif terhadap parameter kualitas air yang diizinkan dengan melihat angka pada perhitungan dengan menggunakan metode indeks pencemar (Nemerow, 1974 dalam KepMenLH No.115 tahun 2003). Indeks Pencemar dapat diperuntukan di badan air suatu sungai untuk mengetahui kondisi tingkat pencemar di badan air, dengan menggunakan rumus sebagai berikut:

1. Parameter yang jika konsentrasi lebih rendah dari baku mutu maka kualitas air akan membaik.

$$
\left(\text { Ci } / \text { Lij)baru }=\frac{\text { Konsentrasi }\left(\frac{\mathrm{mg}}{\text { liter }}\right)}{\text { Nilai Baku Mutu }\left(\frac{m g}{l i t e r}\right)}\right.
$$

2. Parameter yang jika konsentrasi lebih tinggi dari baku mutu maka kualitas air akan membaik.

$$
(C i / L i j) \text { baru }=\frac{\text { Cim-Ci(hasil pengukuran })}{\text { Cim-Lij }} \text {. }
$$

3. Parameter yang memiliki rentang dapat dihitung sebagai berikut:

$\mathrm{C}_{\mathrm{i}} \leq \mathrm{L}_{\mathrm{i}}$ rata - rata, maka perhitungannya akan menjadi:

$$
(C i / L i j) \text { baru }=\frac{(\text { Ci-Lij)rata-rata }}{((\text { Lij)minimum-(Lij)rata-rata })} \text {.... }
$$

$\mathrm{C}_{\mathrm{i}}>\mathrm{L}_{\mathrm{i}}$ rata - rata, perhitungannya menjadi:

$$
(C i / L i j) \text { baru }=\frac{(\text { Ci }- \text { Lij }) \text { rata-rata }}{((\text { Lij)maksimum-(Lij)rata-rata })} \text {... }
$$

4. Apabila nilai $\left(\mathrm{C}_{\mathrm{i}} / \mathrm{L}_{\mathrm{ij}}\right)$ lebih besar dari 1 maka :

$\left(\mathrm{C}_{\mathrm{i}} / \mathrm{L}_{\mathrm{ij}}\right)$ baru $=1,0+\mathrm{P} \cdot \log \left(\mathrm{C}_{\mathrm{i}} / \mathrm{L}_{\mathrm{ij}}\right)_{\text {hasil pengukuran }}$

5. Penentuan indeks pencemar:

$$
P I j=\frac{\sqrt{\sqrt{ }\left(\frac{C i}{L i j}\right)^{2} M+\left(\frac{C i}{L i j}\right)^{2} R}}{2} .
$$

Keterangan: $\mathrm{Ci} \quad=$ Konsentrasi berdasarkan kualitas air

$$
\begin{array}{ll}
\mathrm{Lij} & =\text { Baku Mutu } \\
\mathrm{Pij} & =\text { Indeks Pencemar }
\end{array}
$$

Metode Indeks Pencemar dapat menghubungkan tingkat pencemaran di badan air dengan melihat nilai indeks pencemar. Evaluasi terhadap nilai PI yaitu:

$$
\begin{array}{ll}
0 \leq \mathrm{PI}_{\mathrm{j}} \leq 1 & =\text { Memenuhi Baku Mutu (Kondisi Baik) } \\
1<\mathrm{PI}_{\mathrm{j}} \leq 5 & =\text { Cemar Ringan } \\
5<\mathrm{PI}_{\mathrm{j}} \leq 10 & =\text { Cemar Sedang } \\
\mathrm{PI}_{\mathrm{j}}>10 & =\text { Cemar Berat }
\end{array}
$$


D. Potensi Beban Pencemar Sektor Pertanian

Cara untuk menghitung potensi beban pencemar yang dihasilkan dari pertanian dapat dihitung dengan rumus:

$$
\text { PBPta }=\frac{\text { Ata } \times \text { Ei } \times \alpha}{\text { musim tanam }}
$$

PBPta $=$ Potensi beban pencemar pertanian $(\mathrm{kg} / \mathrm{hari})$

Ata $=$ Luas pertanian $(\mathrm{Ha})$

Ei $\quad=$ Faktor emisi sektor pertanian $(\mathrm{kg} / \mathrm{ha} / \mathrm{musim}$ tanam $)$

$\alpha \quad=$ Runoff

Nilai Runoff yang digunakan untuk potensi beban pencemar jenis lahan pertanian sawah yaitu $10 \%$ dimana sebanyak $90 \%$ air terinfiltrasi kedalam tanah sedangkan nilai runoff yang digunakan untuk potensi beban pencemar jenis lahan pertanian kebun yaitu $1 \%$. Dalam menghitung beban pencemaran dari sektor pertanian faktor emisi yang digunakan pada kegiatan pertanian dilihat pada Tabel 1.

Tabel 1. Faktor Emisi Limbah Sektor Pertanian

\begin{tabular}{lllllll}
\hline No & $\begin{array}{c}\text { Jenis } \\
\text { Pertanian }\end{array}$ & \multicolumn{5}{c}{ Limbah Pertanian } \\
\cline { 3 - 7 } & & BOD & N & P & TSS & Pestisida \\
\cline { 3 - 7 } & & \multicolumn{3}{c}{ Kg/Ha/Musim Tanam } & $\begin{array}{l}\text { L/Ha/Musim } \\
\text { tanam }\end{array}$ \\
\hline 1 & Sawah & 225 & 20 & 10 & 0,4 & 0,16 \\
\hline 2 & Palawija & 125 & 10 & 5 & 2,4 & 0,08 \\
\hline 3 & $\begin{array}{l}\text { Perkebunan } \\
\text { lain }\end{array}$ & 32,5 & 3 & 1,5 & 1,6 & 0,024 \\
\hline
\end{tabular}

Sumber: Iskandar 2007

\section{HASIL DAN PEMBAHASAN}

Status mutu air dilakukan untuk mengetahui kualitas badan air untuk mengklasifikasikan badan air tersebut termasuk badan air yang tercemar atau tidak. Perhitungan status mutu air di Sub DAS Cibeureum dilakukan untuk mengetahui Sub DAS Cibeureum termasuk kedalam sungai tercemar berat, sedang atau tidak. Perhitungan status mutu air dilakukan dengan memiliki data kualitas air Sub DAS Cibeureum yang merupakan data kualitas air yang sudah dipantau oleh DLH Kota Cimahi. Data kualitas air yang akan dihitung yaitu data Pada bulan November 2018 pada bagian hulu dengan menggunakan metode indeks pencemar. Berikut merupakan contoh perhitungan status mutu air menggunakan indeks pencemar di Sub DAS Cibeureum: 


\section{Parameter yang tidak memiliki rentang (BOD):}

Nilai BOD (Cij)

$$
=4,97 \mathrm{mg} / \mathrm{L}
$$

Baku Mutu BOD (Lij)

$$
=3 \mathrm{mg} / \mathrm{L}
$$

$\mathrm{Ci} / \mathrm{Lij}$

$$
=\frac{4,97 \mathrm{mg} / \mathrm{l}}{3 \mathrm{mg} / \mathrm{l}}=1,656
$$

$\mathrm{Ci} / \mathrm{Lij}$ baru

$=1+\mathrm{P} \cdot \log (\mathrm{Ci} / \mathrm{Lij})_{\text {hasil pengukuran }}$

$=1+5 \log (1,656)$

$=2,1$

\section{Parameter yang memiliki rentang $(\mathrm{pH})$ :}

Nilai $\mathrm{pH}$

$$
=7,2
$$

Baku Mutu pH

$$
=6-9
$$

$\mathrm{Ci} / \mathrm{Lij}$

$$
=\frac{(C i-(L i j) \text { rata }- \text { rata })}{\{(\text { Lij }) \text { maksimum }-(\text { Lij }) \text { rata }- \text { rata }\}}=\frac{(7,2-7,5)}{(9-7,5)}=0,2
$$

\section{Parameter yang jika rendah maka kualitas air akan menurun (DO):}

Nilai DO

$$
=1,13 \mathrm{mg} / \mathrm{l}
$$

Baku Mutu DO = $\quad=4 \mathrm{mg} / \mathrm{l}$

DO Jenuh

$$
=8,26
$$

$\mathrm{Ci} / \mathrm{Lij}$

$$
=\frac{\text { Cimaks }- \text { Ci }(\text { Pengukuran })}{\text { Cimaks }- \text { Lij }}=\frac{8,26-1,13}{8,26-4}=1,674
$$

$\mathrm{Ci} / \mathrm{Lij}$ Baru

$$
\begin{aligned}
& =1+P \cdot \log \left(\frac{C i}{L i j}\right) \text { hail pengukuran } \\
& =1+5 \times \log (1,674) \\
& =2,118
\end{aligned}
$$

\section{Indeks Pencemar}

$$
\begin{aligned}
\mathrm{PIj} & =\frac{\sqrt{\left(\frac{C i}{L i j}\right)^{2} M+\left(\frac{C i}{L i j}\right)^{2} R}}{2} \\
& =\frac{\sqrt{22,05^{2}+2,47^{2}}}{2}=11,09 \text { (Cemar Berat) }
\end{aligned}
$$

Berdasarkan hasil perhitungan dengan menggunakan metode indeks pencemar, Sub DAS Cibeureum termasuk ke dalam sungai yang tercemar berat karena data yang didapat untuk Sungai Cibeureum Hulu adalah sebesar 11,09. Data yang digunakan dalam menghitung status mutu air yaitu data berupa baku mutu yang didapat dari DLH Kota Cimahi dengan menggunakan baku mutu kelas II. Pemilihan baku mutu kelas II pada Sungai Cibeureum didasarkan pada Peraturan Pemerintah Nomor 82 Tahun 2001 tentang Pengelolaan Kualitas Air dan Pengendalian Pencemaran Air.

\section{Potensi Beban Pencemaran (PBP) Sektor Pertanian}

Perhitungan potensi beban pencemar dilakukan untuk mengetahui potensi pencemaran yang dihasilkan dari beberapa sektor di Sub DAS Cibeureum dengan proyeksi selama 
lima tahun mendatang. Sektor pertanian merupakan salah satu sektor yang memberi kontribusi pencemaran di Sub DAS Cibeureum. Sawah dan kebun merupakan sumber pencemar yang mencemari Sub DAS Cibeureum. Peta sektor pertanian di Sungai Cibeureum dapat dilihat pada Gambar 2.

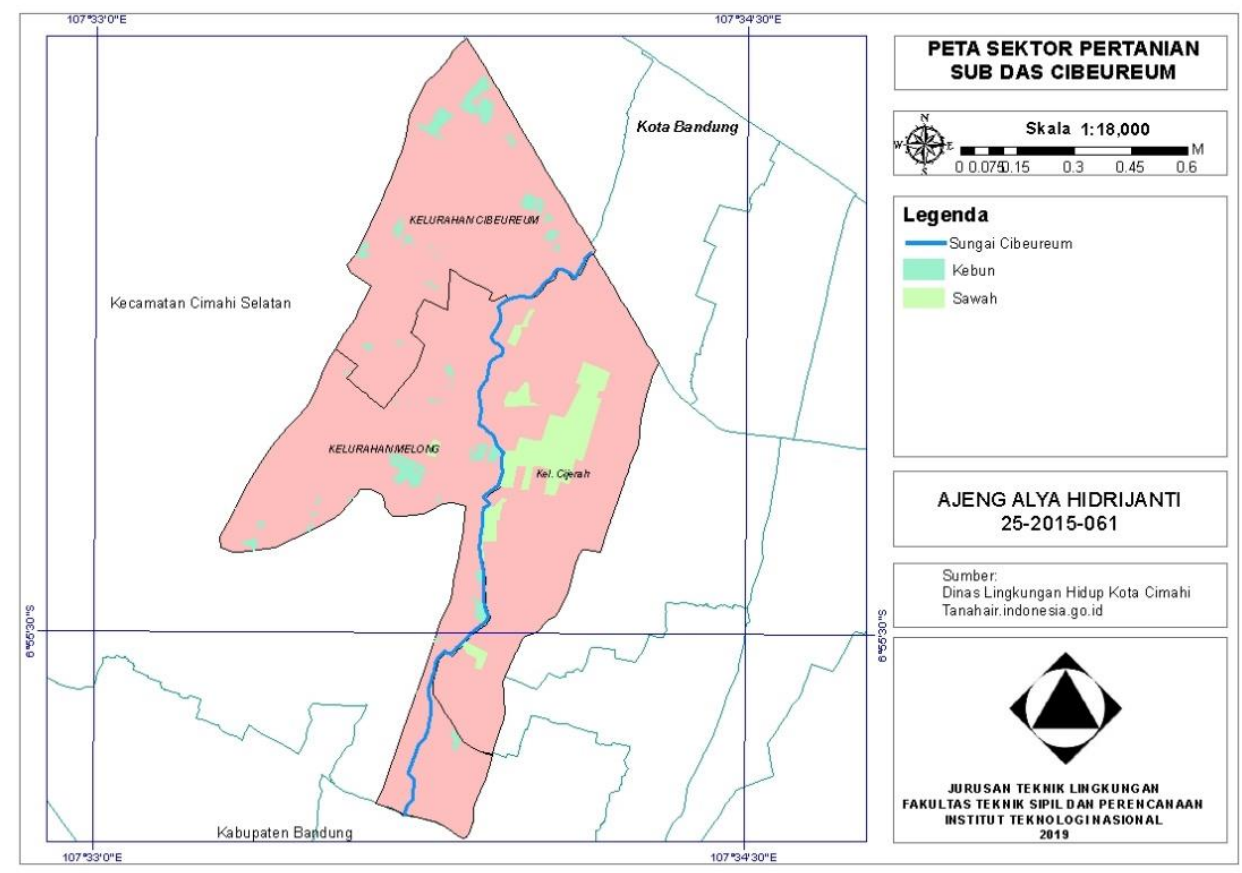

Gambar 2. Peta Sektor Pertanian Sub DAS Cibeureum

Luas pertanian di Sub DAS Cibeureum untuk luas sawah tidak terlalu besar dibandingkan dengan luas kebun, karena tataguna lahan di daerah Sub DAS Cibeureum sudah banyak pemukiman penduduk. Luas pertanian yang terdapat di Sub DAS Cibeureum dapat dilihat pada Tabel 2.

Tabel 2. Luas Lahan Sektor Pertanian Sub DAS Cibeureum

\begin{tabular}{|c|c|c|c|}
\hline \multirow[t]{2}{*}{ No } & \multirow[t]{2}{*}{ Kecamatan } & \multicolumn{2}{|c|}{ Luas (Ha) } \\
\hline & & Sawah & Kebun \\
\hline 1 & Cimahi Selatan & 0,274 & 11,61 \\
\hline
\end{tabular}

Sumber : Hasil Analisa, 2019

Data yang dibutuhkan dalam melakukan perhitungan beban pencemar pada sektor pertanian adalah luas lahan, faktor emisi lahan serta jumlah hari tanam. Sedangkan untuk parameter yang dihitung adalah BOD, TSS, Total-N dan Total P. Faktor emisi limbah dari sektor pertanian dilihat pada Tabel 3. 
Tabel 3. Faktor emisi limbah sektor pertanian

\begin{tabular}{lllllll}
\hline No & Jenis & \multicolumn{5}{c}{ Limbah Pertanian } \\
\cline { 3 - 7 } & Pertanian & BOD & N & P & TSS & Pestisida \\
\cline { 3 - 7 } & & Kg/Ha/Musim Tanam & $\begin{array}{l}\text { L/Ha/Musim } \\
\text { tanam }\end{array}$ \\
\hline 1 & Sawah & 225 & 20 & 10 & 0,4 & 0,16 \\
\hline 2 & Palawija & 125 & 10 & 5 & 2,4 & 0,08 \\
\hline 3 & $\begin{array}{l}\text { Perkebunan } \\
\text { lain }\end{array}$ & 32,5 & 3 & 1,5 & 1,6 & 0,024 \\
\hline
\end{tabular}

Sumber: Iskandar 2007

Contoh perhitungan beban pencemaran sektor pertanian sawah dengan parameter BOD di Cimahi Selatan adalah sebagai berikut:

$$
\begin{gathered}
\text { PBPta }=\frac{\text { Ata } \times \text { Ei } \times \alpha}{\text { musim tanam }} \\
\text { PBPta }=\frac{0,274 \text { Ha } \times 225 \frac{\mathrm{kg}}{\mathrm{ha}} / \text { musimtanam } \times 10 \%}{365 \text { hari }} \\
=0,01689 \mathrm{~kg} / \text { hari }
\end{gathered}
$$

Hasil beban pencemar sektor pertanian sawah di Cimahi Selatan pada tahun 2018 untuk

\begin{tabular}{|c|c|c|c|c|c|c|}
\hline \multirow[t]{2}{*}{ No } & \multirow[t]{2}{*}{ Kecamatan } & \multirow{2}{*}{$\begin{array}{c}\text { Luas } \\
\text { sawah } \\
\text { (Ha) }\end{array}$} & \multicolumn{4}{|c|}{ Beban pencemar (kg/hari) } \\
\hline & & & BOD & Total N & $\begin{array}{c}\text { Total } \\
\mathrm{P}\end{array}$ & TSS \\
\hline 1 & $\begin{array}{l}\text { Cimahi } \\
\text { Selatan }\end{array}$ & 0,274 & 0,01689 & 0,0015 & 0,0008 & 0,000003 \\
\hline
\end{tabular}
parameter BOD, Total-N, Total-P, dan TSS dapat dilihat pada Tabel 4.

Tabel 4. Beban pencemar pertanian sawah tahun 2018

Sumber : Hasil Analisa, 2019

Luas lahan sawah di Kecamatan Cimahi Selatan Sub DAS Cibeureum seluas 0,274 Ha dengan faktor emisi BOD $225 \mathrm{~kg} / \mathrm{ha} /$ musim tanam dikalikan dengan 10\%. Angka 10\% merupakan penggunaan pupuk pada lahan sawah karena sawah lebih banyak mengandung Nitrogen, Posfat, dan Kalium.

Kebun juga merupakan pencemar dari sektor pertanian. Perhitungan potensi beban pencemaran kebun Kecamatan Cimahi Selatan dengan parameter BOD dapat dilihat pada contoh berikut dan hasil beban pencemar pertanian kebun tahun 2018 dapat dilihat pada Tabel 5. 


$$
\begin{gathered}
\text { PBPkebun }=\frac{\text { Ata } \times \text { Ei } \mathrm{x} \alpha}{\text { musim tanam }} \\
\text { PBPkebun }=\frac{11,61 \times 32,5 \frac{\mathrm{kg}}{\mathrm{ha}} / \text { musim tanam } \times 1 \%}{365 \text { hari }} \\
=0,103 \mathrm{~kg} / \text { hari } \\
\text { PBPkebun }=\frac{\text { Ata } \times \text { Ei } \mathrm{x} \alpha}{\text { musim tanam }} \\
\text { PBPkebun }=\frac{11,61 \times 32,5 \frac{\mathrm{kg}}{\mathrm{ha}} / \text { musim tanam } \times 1 \%}{365 \text { hari }}=0,103 \mathrm{~kg} / \text { hari }
\end{gathered}
$$

Tabel 5. Beban pencemar pertanian kebun tahun 2018

\begin{tabular}{ccccccc}
\hline No & Kecamatan & Luas kebun & \multicolumn{4}{c}{ Beban pencemar (kg/hari) } \\
\cline { 4 - 7 } & & (Ha) & BOD & Total N & Total P & TSS \\
\hline \multirow{2}{*}{1} & Cimahi & 11,61 & 0,103377 & 0,009542 & 0,0048 & 0,005089315 \\
& Selatan & & & & & \\
\hline
\end{tabular}

Sumber: Hasil Analisa, 2019

Luas lahan perkebunan di Kecamatan Cimahi Selatan Sub DAS Cibeureum seluas 11,61 Ha dengan faktor emisi BOD 32,5 kg/ha/musim tanam dikalikan dengan $1 \%$ yang merupakan kebun tidak banyak menggunakan pupuk. Dari Tabel 5. Dapat dilihat parameter BOD merupakan parameter yang memiliki beban pencemar paling besar daripada parameter total-N, total P dan TSS yaitu dengan nilai beban pencemar paling besar pada sawah dengan nilai $0,01689 \mathrm{~kg} /$ hari dan pada kebun sebesar 0,103377 $\mathrm{kg} /$ hari. Hal tersebut menandakan bahwa BOD merupakan indikator yang menandakan adanya organik dalam pertanian di Sub DAS Cibeureum.

\section{PENUTUP}

Diketahui bahwa status mutu Sungai Cibeureum termasuk sungai yang tercemar berat dengan hasil 11,09 dengan menggunakan metode indeks pencemar. Beban pencemar sektor pertanian sawah Sub DAS Cibeureum pada tahun 2018 sebesar 0,01689 kg/hari BOD, 0,001501 kg/hari Total-N, 0,0008 kg/hari Total-P, dan 0,000003 kg/hari TSS. Beban pencemar sektor pertanian kebun Sub DAS Cibeureum pada tahun 2018 sebesar 0,103377 kg/hari BOD, 0,009542 kg/hari Total-N, 0,0048 kg/hari Total-P, dan 0,00508 $\mathrm{kg} / \mathrm{hari}$ TSS. Beban pencemar sektor pertanian pada tahun proyeksi tetap sama seperti tahun 2018 karena dalam Perda Kota Cimahi Nomor 4 Tahun 2013 tentang Rencana Tata Ruang dan Wilayah Kota Cimahi Tahun 2012-2032 dijelaskan pada sektor pertanian tidak mengalami rencana pengembangan kawasan budidaya karena sektor tersebut termasuk ke dalam kawasan budidaya.

\section{DAFTAR PUSTAKA}

DIKPLHD Kota Cimahi. 2018. Dokumen Informasi Kinerja Pengelolaan Lingkungan Hidup Daerah (DIKPLHD) Kota Cimahi Tahun 2018. Cimahi: Kantor Lingkungan Hidup Pemerintah Daerah Kota Cimahi.

Dinas Lingkungan Hidup Kota Cimahi. 2018. Cimahi. Indonesia.

Effendi, Iskandar. 2003. Telaah Kualitas Air. Yogyakarta: Kanisius. 
Iskandar, Iskandar. 2007. Panduan Pelatihan Pengelolaan Kualitas Air. Jakarta: Puslitbang Sumber Daya Air Kementerian Pekerjaan Umum.

KepMenLH No. 115 tahun 2003 tentang Pedoman Penentuan Status Mutu Air.

Kurniasih, Nia. 2002. Pengelolaan DAS Citarum Berkelanjutan. Jurnal Teknologi Lingkungan. Volume 3. 82-92.

Peraturan Menteri Lingkungan Hidup Nomor 1 Tahun 2010 tentang Tata Laksana Pengendalian Pencemaran Air, (2010).

Peraturan Daerah Kota Cimahi Nomor 4 Tahun 2013 Tentang Rencana Tata Ruang Wilayah Kota Cimahi Tahun 2012-2032.

Undang-Undang Republik Indonesia Nomor 7 Tahun 2004 Tentang Sumber Daya Air.

Robinson, Hisky., Juwana., dan Marganingrum. (2018). Kajian Perhitungan Beban Pencemaran Sungai Cisangkuy di Cekung Bandung dari Sektor Pertanian. Jurnal Rekayasa Hijau, Volume 2. 165-175. 